\title{
Review
}

\section{Music Therapy in Hospice and Palliative Care: a Review of the Empirical Data}

\author{
Russell E. Hilliard \\ Music Department, State University of New York at New Paltz, New Paltz, NY, USA
}

\begin{abstract}
Although music therapy is an established allied health profession and is used with increasing frequency in the treatment of those with a terminal illness, there is a real dearth of empirical research literature supporting the use of music therapy in end-of-life care. This article reviews the empirical studies found in the literature and documents the emergence of an evidenced-based approach to the use of music therapy in hospice and palliative care. A total of 11 studies are reviewed; of these, six show significant differences supporting the use of music therapy in this area. Dependent variables positively affected by music therapy include pain, physical comfort, fatigue and energy, anxiety and relaxation, time and duration of treatment, mood, spirituality and quality of life. Guidelines for future research are considered, and variables that need to be controlled are presented. The need to create an evidence-based approach to hospice and palliative care music therapy is articulated, and future researchers are empowered to continue to conduct investigations among this population.
\end{abstract}

Keywords: complementary arts - hospice - music - music therapy - palliative care

\section{Introduction}

Music therapy is a growing service provided in end-of-life care, with music therapists gaining employment opportunities in hospices and as members of palliative care teams in hospitals each year. With new music therapy programs being implemented in hospice and palliative care, more patients and families have access to this service (1). In addition, data from a survey study of 300 randomly selected hospices indicated that the most popular forms of complementary therapies were massage therapy and music therapy (2). The primary goal of palliative care is to promote patients' quality of life by alleviating physiological, psychological, social and spiritual distress, and improving comfort. Although there are several forms of complementary therapy (e.g. massage, art therapy, aromatherapy, reflexology, therapeutic touch), this article evaluates the music therapy literature and provides data on the emergence of an evidenced-based approach to music therapy in end-of-life care.

Music therapy is an established allied health profession, and music therapists are Board Certified (MT-BC) by the

For reprints and all correspondence: Dr Russell E. Hilliard, State University of New York at New Paltz, Music Department, 75 South Manheim Boulevard, New Paltz, NY 12561, USA. Tel: +1 845257 2708; E-mail: rehmt@aol.com
Certification Board for Music Therapists (CBMT) upon the completion of at least an undergraduate degree in music therapy or its equivalent, a clinical internship (averaging 1040 hours), and successfully passing the CBMT examination. In hospice and palliative care, music therapists use methods such as song writing, improvisation, guided imagery and music, lyric analysis, singing, instrument playing and music therapy relaxation techniques to treat the many needs of patients and families receiving care. Needs often treated by music therapists in end-of-life care include the social (e.g. isolation, loneliness, boredom), emotional (e.g. depression, anxiety, anger, fear, frustration), cognitive (e.g. neurological impairments, disorientation, confusion), physical (e.g. pain, shortness of breath) and spiritual (e.g. lack of spiritual connection, need for spiritually-based rituals) (3-10).

The literature on music therapy in end-of-life care is rich in qualitative studies. Most of these provide descriptions of music therapy programs in hospices or hospital-based palliative care units and utilize case examples to illustrate how music therapy addressed patient and family needs (11-21). Theories on the use of music therapy have been published in the literature, and they describe the various theoretical perspectives in the utilization of music for people who are dying. Elisabeth Kubler-Ross recognized the value of music therapy in helping dying patients who

(C) The Author (2005). Published by Oxford University Press. All rights reserved.

The online version of this article has been published under an open access model. Users are entitled to use, reproduce, disseminate, or display the open access version of this article for non-commercial purposes provided that: the original authorship is properly and fully attributed; the Journal and Oxford University Press are attributed as the original place of publication with the correct citation details given; if an article is subsequently reproduced or disseminated not in its entirety but only in part or as a derivative work this must be clearly indicated. For commercial re-use, please contact journals.permissions@oupjournals.org 
Table 1. Empirical studies in hospice/palliative care music therapy

\begin{tabular}{|c|c|c|c|c|c|c|}
\hline Author & Year & Publication type & Research design & Randomization & $n$ & Dependent variables \\
\hline Curtis & 1986 & Journal & Alternating treatment & Yes & 9 & Pain relief and relaxation \\
\hline Whittall & 1989 & $\begin{array}{l}\text { Conference } \\
\text { proceedings }\end{array}$ & $\begin{array}{l}\text { Pilot study; pre/post } \\
\text { test }\end{array}$ & No & 8 & $\begin{array}{l}\text { Heart and respiratory rate, } \\
\text { extremity temperature }\end{array}$ \\
\hline Calovini & 1993 & Master's thesis & Pre/post test & No & 11 & State anxiety \\
\hline Longfield & 1995 & Master's thesis & $\begin{array}{l}\text { Quasi-experimental } \\
\text { pre/post test }\end{array}$ & No & 8 & Mood and pain \\
\hline Krout & 2001 & Journal & Pre/post test & No & 80 & Comfort, pain, relaxation \\
\hline Hilliard & 2003 & Journal & Clinical trial & Yes & 80 & $\begin{array}{l}\text { Quality and length of life; time } \\
\text { of death }\end{array}$ \\
\hline Wlodarczyk & 2003 & Master's thesis & $\mathrm{ABAB}$; counter-balance & No & 10 & Spirituality \\
\hline
\end{tabular}

$\mathrm{ABAB}$, session A consisted of cognitive-behavioral music therapy (30 min) and session B consisted of a non-music visit (30 min); MT, music therapy.

are withdrawn become more engaged with others (22). Others have provided theoretical frameworks for the use of music therapy for people nearing the end of their life (23-27). Phenomenological research has been used to document the process of music therapy with patients who have a terminal illness (28-30). Modified grounded theory and content analysis have been used in the literature to categorize lyrical themes in songs written by terminally ill patients $(31,32)$. Primary caregivers of hospice patients who had received complementary therapies, including music therapy, reported that the therapies had improved the patients' quality of life (33).

\section{Empirical Data}

Although the research literature includes many qualitative studies and perspectives on the use of music therapy in hospice and palliative care, the empirical data are limited. Table 1 lists the 11 empirical studies evaluating the use of music therapy for people with a terminal illness found within the research literature. Databases such as Article First, First Search, Medline, ERIC, LexisNexis and PsychInfo were used to locate the research articles. Five of the studies were published in scholarly journals (e.g. Journal of Music Therapy and American Journal of Hospice and Palliative Care). Another five were unpublished master's theses, and one was from a book of conference proceedings. What follows is a summary of each of these studies and an analysis of the body of evidence for hospice/palliative care music therapy.

\section{Single Music Therapy Sessions Exert Limited Ability to Decrease Anxiety}

Curtis (34) conducted an empirical study to evaluate the effects of music on pain relief and relaxation of patients with a terminal illness. Five females and four males diagnosed with a terminal illness were included in the study. The experimental conditions implemented were as follows: (A) no intervention, subjects did not receive music therapy; (B) background sound, subjects were instructed to relax while listening to a 15 -min tape of hospital sounds; and (C) music, subjects were instructed to relax while listening to a 15-min tape of calm, preferred instrumental music. These conditions were implemented twice daily for 10 days, and subjects were randomly assigned to one of two orders of experimental conditions in this alternating treatments design: ABACA $(n=5)$ and ACABA $(n=4)$. Subjects self-rated the four dependent variables (pain relief, physical comfort, contentment and relaxation) using a modified graphic rating scale. Although statistical analysis (Friedman two-way analysis of variance) indicated no significant differences in the dependent variables under the different treatment conditions, a graphic analysis of individual responses indicated that music may have been effective. The researcher suggested that replication of the study with a larger number of subjects and longer duration would allow for results to be generalized.

Whittall (35) conducted an empirical pilot study documenting the effects of music therapy on anxiety among those with a terminal illness. Eight adult patients with advanced malignant disease from the Royal Victoria Hospital's Palliative Care Service were included in the study. Using non-invasive biofeedback equipment, the subjects' heart and respiratory rates and extremity temperature were measured $10 \mathrm{~min}$ before music, every 10 min during the 30-min music therapy session and 10 min after music therapy. Guided imagery, deep breathing and muscle relaxation exercises were components of the music therapy sessions. Mean heart rate scores decreased from 85.8 beats $\mathrm{min}^{-1}$ before music therapy to 77.1 beats $\mathrm{min}^{-1}$ following music therapy, and respiratory rates decreased from 19.5 to 15.4 breaths $\mathrm{min}^{-1}$ after music therapy. Extremity 
temperature increased from 84.8 to $87.9^{\circ} \mathrm{F}$, and the researcher indicated that the increase in temperature may suggest vasodilation with relaxation. The limitations of the pilot study included the lack of a control group and the small number of subjects, yet the results of the study encouraged future research with a larger number of subjects.

Calovini's (36) master's thesis in music therapy studied the effects of participation in one music therapy session on state anxiety in hospice patients. Nurses and social workers referred the 11 adult subjects to the music therapist for participation in the study, and data were collected for 4 months. Eight of the subjects were receiving music therapy before the beginning of the study, and all subjects had been diagnosed with a terminal illness (cancer, pulmonary disease, emphysema and congestive heart failure). The study utilized a pre-test and post-test design with various measurements for anxiety: a self-reporting questionnaire (adapted from Spielberger's State-Trait Anxiety Inventory (STAI)) and physiological measures (blood pressure, pulse rate and finger temperature). Music therapy was offered in one of three forms:(i) listening to music and singing, (ii) learning to play an instrument or (iii) using relaxation techniques to music. Each subject chose the type of music therapy desired during the session. There were no statistically significant differences in pre-test and post-test comparisons for the subjects as measured by systolic and diastolic blood pressure, pulse rate, finger temperature and the anxiety questionnaire. The author concluded that single music therapy sessions were limited in their ability to decrease anxiety, and she recommended that further studies use measurement tools designed specifically for the terminally ill.

For her master's thesis in nursing, Longfield (37) conducted a quasi-experimental study measuring the effects on mood and pain in hospice patients receiving music therapy. Eight adult subjects diagnosed with cancer comprised their own control group and received music therapy via taped recordings and a headset for $45 \mathrm{~min} \mathrm{day}^{-1}$ for 5 days. The pre-test and post-test measurements used the Short-Form McGill Pain Questionnaire (SFMPQ) and the Linear Analog Self-Assessment Scale (LASA). All subjects were prescribed narcotic pain medications and continued taking medications as prescribed during the study. Inferential statistics (paired $t$-tests) were used to compare difference scores from pre-test to post-test. There was a significant decrease in pain $(P<0.001)$ as measured by the SFMPQ, and scores from the LASA showed a positive increase in mood for fatigue, anxiety and energy. The author concluded that although her study supported the use of music therapy, further research with larger sample sizes was necessary.

\section{Treatment of Discomfort with Music Therapy}

In a pilot study with an ex post facto design, a computerized database for music therapy in palliative care was utilized. The goals of the study were (i) to describe a tool for research, (ii) to evaluate the use of the computerized database and (iii) to investigate the efficacy of music therapy. The database was designed working with a computer consultant and familiar computer programs. Several tools were used for assessment and data collection, and they consisted primarily of visual analog scales (VASs) using separate scales for different problems (i.e. mood, pain, anxiety and shortness of breath). Over a period of 1 year, 150 patients were seen, and 90 of their initial music therapy sessions were analyzed. A pre-test and post-test with the VASs were used, and the data were analyzed using the Wilcoxon signed rank test at the $P<0.05$ level. Statistical significance was found for patient-rated scores for pain, mood and anxiety following music therapy. There was no significance for shortness of breath. Although the author acknowledged that this study was limited because subjects were not randomly assigned and it used an ex post facto design, the data indicated that music therapy is beneficial for people suffering from pain, mood distortions and anxiety within the palliative care treatment model (38).

In an empirical study of single-session music therapy, Krout (39) studied the effects of music therapy on pain, physical comfort and relaxation among 80 hospice patients over a total of 90 sessions. Although the number of sessions ranged from one to four for each subject, the average number was one session (74 subjects received only single sessions). Subjects had been referred to music therapy and had a wide range of diagnoses; they were being served in the hospital, their own homes, nursing homes, assisted living facilities and an in-patient hospice setting. Patient data were collected in two ways: independent observation and self-reporting. Music therapy sessions were provided in unique ways for each patient, based on individual clinical needs; however, active and passive experiences were utilized with live music. Using one-tailed $t$-tests, data analysis indicated a significant difference $(P \leq 0.001)$ for observer-rated changes in pain, physical comfort and relaxation after the music therapy sessions. From the self-rated changes there was also a significant difference $(P \leq 0.005)$ on the three dependent variables. The author recognized the following limitations of the study: the treatment strategy used multiple interventions, data were observed primarily over single sessions rather than evaluating the effects of multiple sessions over time and the data were not compared with interventions not based on music therapy.

In a study on the effects of vocal improvisation on discomfort behaviors of in-patient hospice clients, Batzner (40) documented a decrease in discomfort behaviors of clients receiving music therapy. Participants $(n=15)$ had various terminal diagnoses, excluding dementia, and were randomly assigned to one of two conditions: (i) music or (ii) no music. Each condition utilized an ABA format, where $\mathrm{A}=5$-min baseline and $\mathrm{B}=10$-min intervention. In the music condition, the music therapist improvised vocally with guitar accompaniment, and in the no-music condition, the music therapist visited with participants. Sessions were videotaped and discomfort behaviors were tallied. Graphic analysis indicated a decrease in discomfort behaviors for those receiving music therapy.

\section{Music Therapy and Spirituality}

Because many people facing the end of life often request spiritual/religious music, Wlodarczyk (41) investigated the 
effect of music therapy on the spirituality of people in an in-patient hospice unit. Participants $(n=10)$ were adults newly admitted to the in-patient hospice house; they were able to complete a questionnaire and respond verbally, and to consent to participate in the study. Diagnosis, age, gender and religious preference were not controlled for in this study. Participants served as their own control in an $\mathrm{ABAB}$ research design, where session A consisted of cognitive-behavioral music therapy (30 $\mathrm{min}$ ) and session B consisted of a non-music visit (30 min). The design was counterbalanced (BABA) for half of the participants to control for order effect. Spirituality was measured using the 18-item Spiritual Well-Being Scale (SWBS) and was completed by participants following each condition. Statistical analyses indicated a significant increase in scores on the SWBS on the days in which music therapy was provided. The study supports the use of music therapy to increase spiritual well-being for the terminally ill.

\section{Quality-of-Life Enhancement with Music Therapy}

Abbott's (42) master's thesis documented the effects of music therapy on the quality of life of patients with a terminal illness. Music therapists from three hospices selected the 28 adult subjects for the study, and subjects were divided into music and non-music groups by therapist selection. Diagnoses of subjects included cancer, AIDS, heart disease, pulmonary disease and amyotrophic lateral sclerosis. Quality of life was measured using the Profile of Mood States (POMS) during sessions. Music therapy was provided by music therapists working in the hospices and was designed specifically for each patient. Subjects received at least 5 hours of music therapy in the study. Music therapy techniques employed included listening to music, relaxation to music, playing instruments, lifereview activities, song composition and improvisation. A total of six factors were measured on the POMS, and matched pairs of factors were analyzed using paired $t$-tests. The results indicated that there were no significant differences between the music and non-music groups. It was concluded that the sample size was a confounding factor, and the author suggested that measurement tools such as those that measure physiological changes may be less fatiguing for patients.

In a randomized clinical trial, Hilliard (8) studied the effects of cognitive-behavioral music therapy on quality of life, length of life and time of death in relation to last visit, by discipline, for people diagnosed with terminal cancer who were receiving hospice care services. Participants ( $n=80$ adults) were randomly assigned to one of two conditions: (i) control (routine hospice care services only) or (ii) experimental (routine hospice care services and music therapy). The study controlled for place of residence in that all participants resided in their homes, and conditions were matched by age and sex such that each condition included an equal number of men and women as well as of those over and under age 65 years. Controlling for these variables was important since quality-of-life studies in end-of-life care indicate a need to control for residence, the music therapy literature indicates a need to control for sex and the pain literature indicates a need to control for age. The Hospice Quality-of-Life Index-Revised (HQOLI), a 29-question self-report tool, was used to measure quality of life. Participants in the control condition completed the HQOLI following the social work sessions, and those in the experimental condition completed it following the music therapy sessions. Because music therapists often report qualitatively that music assists the dying in releasing life, this study evaluated the time of death of each participant in the experimental condition in relation to the last visit, by hospice discipline (social worker, nurse and music therapist). Length of life was the last dependent variable in the study, and length of life and time of death were measured using medical record analysis.

Statistical analyses indicated no significant differences in time of death in relation to last visit by discipline or in length of life between treatment conditions. The data do not support the concept that music assists the dying in releasing life, nor that it lengthens life. There was, however, a significant difference for quality of life for participants receiving music therapy. Furthermore, the more music therapy sessions participants received, the higher the quality of life, even as their physical health declined. This was not the case in the control group, where quality of life declined as physical status declined. The study supports the idea that live music therapy sessions increase perceived quality of life for people with terminal cancer, and that sessions should be provided with a relatively high frequency since quality of life increased with each music therapy session.

\section{Music Therapy for Hospice Nursing Home Residents}

In an ex post facto analysis of data, Hilliard (43) evaluated the use of music therapy for residents in nursing homes receiving hospice care. Following their deaths, 80 patients' medical records were reviewed. Using the Hospice Management Systems-Plus software, records were selected randomly for patients who had been referred to music therapy $(n=40)$ and patients who had not $(n=40)$. Length of life was compared between groups, and there was a significant difference (increased length of life) for those who received music therapy. The number and length of sessions provided, by hospice discipline, was analyzed. Statistical analyses indicated that music therapists provided significantly more direct sessions to patients than did social workers, and they spent significantly longer (by minutes) in sessions than did nurses or social workers. Care plan needs were analyzed graphically, and the data indicate that music therapists were the only hospice professionals consistently treating the emotional, spiritual, cognitive, social and physical needs of the patients. Nurses primarily treated only the physical needs, whereas social workers primarily treated the case management needs. Although the study has limitations (lack of randomization, ex post facto design), these data document the fact that music therapists meet important needs of residents in nursing homes receiving hospice care that may otherwise be unmet. 
Table 2. Studies with significant differences

\begin{tabular}{|c|c|c|c|c|}
\hline Author & Year & $\begin{array}{l}\text { Variable(s) with } \\
\text { significance }\end{array}$ & $n$ & Statistical analysis \\
\hline Longfield & 1995 & $\begin{array}{l}\text { Pain, fatigue, } \\
\text { anxiety, energy }\end{array}$ & 8 & Paired $t$-tests \\
\hline Gallagher & 2001 & $\begin{array}{l}\text { Pain, mood, } \\
\text { anxiety }\end{array}$ & 90 & $\begin{array}{l}\text { Wilcoxcon signed } \\
\text { rank test }\end{array}$ \\
\hline Krout & 2001 & $\begin{array}{l}\text { Pain, physical } \\
\text { comfort, relaxation }\end{array}$ & 80 & One-tailed $t$-tests \\
\hline Wlodarczyk & 2003 & Spirituality & 10 & Two-tailed Walsh test \\
\hline Hilliard & 2003 & Quality of life & 80 & $\begin{array}{l}\text { Repeated measures and } \\
\text { two-way ANOVA; } t \text {-tests }\end{array}$ \\
\hline Hilliard & 2004 & $\begin{array}{l}\text { Time and duration } \\
\text { of treatment; } \\
\text { length of life }\end{array}$ & 80 & $\begin{array}{l}\text { Independent samples } \\
t \text {-test; paired samples } \\
t \text {-test }\end{array}$ \\
\hline
\end{tabular}

\section{Reporting the Significance of Music Therapy}

Although empirical studies are beginning to surface in the literature regarding palliative care music therapy, there remains a serious lack of controlled studies with large sample sizes that would allow for generalization. There is a need for studies with higher levels of control and randomization of subjects. Of all of the quantitative studies mentioned here, only two controlled for specific hospice diagnoses $(8,37)$. Subjects with different terminal diagnoses may constitute a confounding variable since death trajectories vary by terminal diagnosis. Lack of randomization is a limitation for most of the studies discussed here; only three used randomization $(8,34,40)$. Of those that used randomization, only one showed significant differences supporting the use of music therapy (8). Most of the sample sizes are small, which limits generalization, but among those with larger sample sizes, there were significant differences supporting the use of music therapy for the terminally ill. Some of the studies evaluated only single music therapy sessions, and Krout (39) argued that future research should evaluate music therapy across multiple sessions. Measurement tools varied, but Calovini (36) encouraged the use of tools designed specifically for the terminally ill. Only one study utilized a measurement tool designed for the terminally ill with established reliability and validity (8). Although the studies have limitations, the results show promise for the use of music therapy in palliative care. Six of the studies cited a statistically significant difference with the use of music therapy (Table 2). Therefore, the results of these studies encourage further research to better understand the use of music therapy in palliative care.

\section{Need for Further Research}

Qualitative studies make up the majority of research support in the area of hospice and palliative care music therapy, but there is a real dearth in the literature of empirical, quantitative studies. Because dying is a complex experience, research needs to be conducted to evaluate the efficacy of the support provided for patients with a terminal illness. Although qualitative studies are valuable in illustrating the use of music therapy for the terminally ill, Bosanquet and Salisbury (44) caution that reliability and the ability to generalize results can be limiting. They recommend that researchers conduct quantitative studies because "the advantages of clearly defined outcome measures include the minimization of potential researcher bias in the interpretation of results and also in the testing of hypotheses" (p. 23). Furthermore, quantitative studies provide greater assurance of reliability and results can be more readily generalized than those of qualitative studies.

From the existing literature on music therapy in hospice and palliative care, guidelines for future studies can be established. Because several investigators acknowledged the small sample size and lack of participant randomization as limitations in their studies, it is important to conduct future research with larger sample sizes and to assign participants randomly to conditions to allow for more rigorous statistical analyses and generalization of results. Psychometric tests with established reliability and validity in hospice and palliative care research have been emerging, and they offer music therapists the opportunity to use measurement tools that are designed specifically for the dying. Using measurement tools designed specifically for the population being studied (i.e. the terminally ill) will assist in strengthening the body of research. Because death trajectories can vary widely depending on diagnosis, it may be important for researchers to control for diagnosis in future research. These suggested guidelines may help future researchers in designing studies that allow for the generalization of results.

Research into hospice and palliative care is important in many ways. Robbins (45) provided four reasons for evaluating palliative care. First, government agencies and other funding sources that provide reimbursement for palliative care seek data to indicate that the services provided meet the needs of the patients and families. Second, hospital administrators and hospice administrators need assurance that the allocation of funds for specialty programs serves to raise the standard of care for patients with a terminal illness. From a palliative care clinician's point of view, the quality of services is paramount. Research needs to be conducted to ensure a high quality of care and to provide for the best clinical interventions in meeting the needs of patients and families. Creating an evidence base in hospice and palliative care music therapy will assist music therapy clinicians in establishing best practices in endof-life care. Finally, new and existing forms of therapy need to be tested to ensure their efficacy. Although research with the terminally ill can be limited owing to ethical considerations, the literature needs to be enriched to include quantitative studies measuring the effects of music therapy on patients who have been diagnosed with a terminal illness.

\section{References}

1. Hilliard RE. Hospice administrators' knowledge of music therapy: A comparative analysis of surveys. Music Ther Perspect 2004;22;104-8.

2. Demmer C. A survey of complementary therapy services provided by hospices. J Palliat Med 2004;7:510-6. 
3. Clements-Cortes A. The use of music in facilitating emotional expression in the terminally ill. Am J Hosp Palliat Med 2004;21:255-60.

4. Cunliffe J. Reflections on pain management: a case study. Int J Palliat Nurs 2003;9:449-53.

5. O'Callaghan CC. Communicating with brain-impaired palliative care patients through music therapy. J Palliat Care 1993;9:53-6.

6. O'Callaghan CC. Pain, music creativity and music therapy in palliative care. Am J Hosp Palliat Care 1996;13:43-9.

7. Salmon D. Music and emotion in palliative care: Accessing inner resources. In: Lee CA (editor), Lonely Waters. Oxford: Sobell Publications, 1995, pp. 71-85.

8. Hilliard RE. The effects of music therapy on the quality and length of life of people diagnosed with terminal cancer. J Music Therapy 2003;40:113-37.

9. Krout RE. The effects of single-session music therapy interventions on the observed and self-reported levels of pain control, physical comfort, and relaxation of hospice patients. Am J Hosp Palliat Care 2001;18:383-90.

10. Magill L. The use of music therapy to address the suffering in advanced cancer pain. J Palliat Care 2001;17:166-72.

11. Mandel SE. The role of the music therapist on the hospice/palliative care team. J Palliat Care 1993;9:37-9.

12. Nakagami Y. Hospice program and palliative medicine. Gan To Kagaku Ryoho 1997;24:792-9.

13. Munro S. Music Therapy in Palliative/Hospice Care. New York: Magnamusic-Baton, Inc. 1984.

14. Hogan B. Music therapy at the end of life: Searching for the rite of passage. In: Aldridge D (editor), Music Therapy in Palliative Care: New Voices. London: Jessica Kingsley Publishers, 1996, 68-81.

15. Weber S. Music: A means of comfort. In: Aldridge D (editor), Music Therapy in Palliative Care: New Voices. London: Jessica Kingsley Publishers, 1996, 95-104.

16. Mandel SE. Music therapy in the hospice: 'Musicalive'. Palliat Med 1991;5:155-60.

17. Starr RJ. Music therapy in hospice care. Am J Hosp Palliat Care 1999;16: 739-42.

18. Marr J. 'At home' with music therapy. In: Broadstock B, Cumming N, Grocke DE et al. (editors), Aflame with Music. Melbourne: Centre for Studies in Australian Music, 1996, 123-9.

19. Hilliard RE. The use of music therapy in meeting the multidimensional needs of hospice patients and families. J Palliat Care 2001;17:161-6.

20. Foxglove T, Tyas B. Using music as a spiritual tool in palliative care. Eur J Palliat Care 2000;7:1-5.

21. Lewis CR, de Vedia A, Reuer B, Schwan R, Tourin C. Integrating complementary and alternative medicine into standard hospice and palliative care. Am J Hosp Palliat Care 2003;20:221-8.

22. Kubler-Ross E. Questions and Answers on Death and Dying. New York: MacMillan Publishing Company, 1974.

23. Gilbert JP. Music therapy perspectives on death and dying. J Music Ther 1977; 14:165-71.

24. West TM. Psychological issues in hospice music therapy. Music Ther Perspect 1994;12:117-24.

25. Salmon D. Music and emotion in palliative care. J Palliat Care 1993;9:42-8

26. Salmon D. Music therapy as psychospiritual process in palliative care. J Palliat Care 2001;17:142-6.
27. Munro S. Music therapy in palliative care. CMAJ 1978;119:1029-34.

28. Forinash M. Research in music therapy with the terminally ill: A phenomenological approach. In: Martin JA (editor), The Next Step Forward: Music Therapy with the Terminally Ill. Bronx, NY: Calvary Hospital, 1989, pp. 73-7.

29. Forinash M. Phenomenological research. In: Wheeler BL (editor), Music Therapy Research: Quantitative and Qualitative Perspectives. Phoenixville, PA: Barcelona, 1995, pp. 367-86.

30. Hogan B. The experience of music therapy for terminally ill patients: A phenomenological research project. In: Pratt RR, Grocke DE (editors), MusicMedicine 3: MusicMedicine and Music Therapy. Faculty of Music, University of Melbourne, Australia: Expanding Horizons, 1999, pp. 242-54.

31. O'Callaghan CC. Lyrical themes in songs written by palliative care patients. J Music Ther 1996;33:74-92.

32. O'Callaghan CC. Bringing music to life: a study of music therapy and palliative care experiences in a cancer hospital. J Palliat Care 2001;17: 155-60.

33. Demmer C, Sauer J. Assessing complementary therapy services in a hospice program. Am J Hosp Palliat Care 2002;19:306-14.

34. Curtis SL. The effect of music on pain relief and relaxation of the terminally ill. J Music Ther 1986;23:10-24.

35. Whittall J. Songs in palliative care: A spouse's last gift. In: Bruscia K (editor). Case Studies in Music Therapy. Phoenixville, PA: Barcelona Publishers, 1991, pp. 603-10.

36. Calovini BS. The effect of participation in one music therapy session on state anxiety in hospice patients. Case Western Reserve University, Cleveland, OH: Unpublished master's thesis, 1993.

37. Longfield V. The effects of music therapy on pain and mood in hospice patients. Saint Louis University, St Louis, MO: Unpublished master's thesis, 1995

38. Gallagher LM. Developing and using a computerized database for music therapy in palliative care. J Palliat Care 2001;17:147-54.

39. Krout RE. The effects of single-session music therapy interventions on the observed and self-reported levels of pain control, physical comfort, and relaxation of hospice patients. Am J Hosp Palliat Care 2001;18: 383-90.

40. Batzner KW. The effects of therapist vocal improvisation on discomfort behaviors of in-patient hospice clients. University of Kansas, Lawrence, KS: Unpublished master's thesis, 2003.

41. Wlodarczyk N. The effect of music therapy on the spirituality of persons in an in-patient hospice unit as measured by self-report. Florida State University, Tallahassee, FL: Unpublished master's thesis, 2003.

42. Abbott CM. The effects of music therapy on the perceived quality of life of patients with terminal illness in a hospice setting. Western Michigan University, Kalamazoo, MI: Unpublished master's thesis, 1995.

43. Hilliard RE. A post-hoc analysis of music therapy services for residents in nursing homes receiving hospice care. J Music Ther 2004 (in press).

44. Bosanquet N, Salisbury C. Providing a Palliative Care Service: Towards and Evidence Base. Oxford: Oxford University Press, 1999.

45. Robbins M. Evaluating Palliative Care: Establishing the Evidence Base. Oxford: Oxford University Press, 1998

Received September 30, 2004; accepted February 23, 2005 


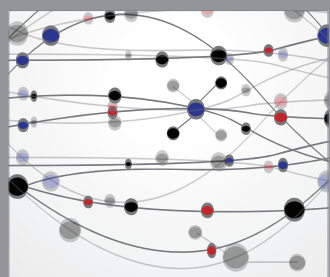

The Scientific World Journal
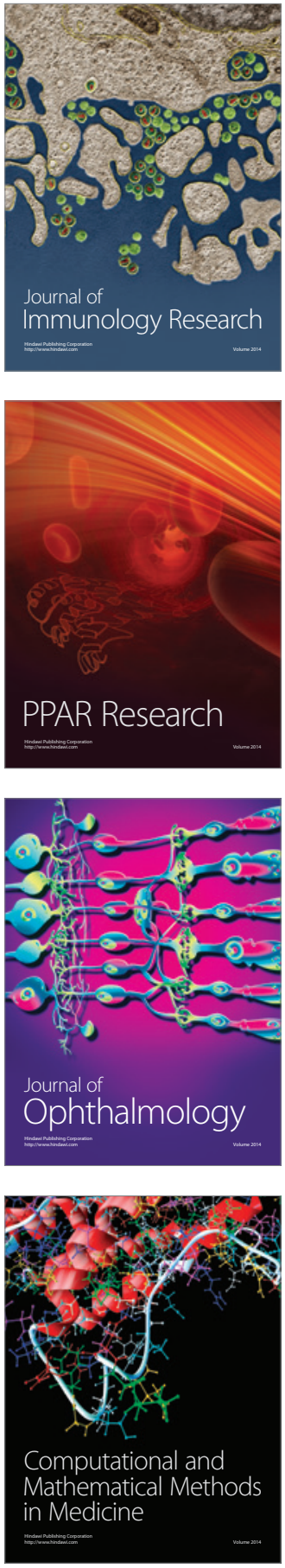

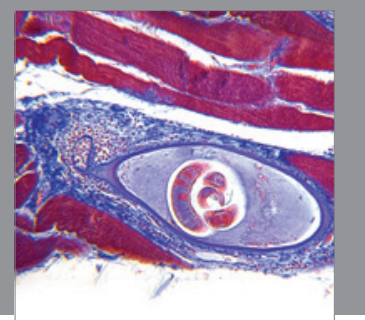

Gastroenterology

Research and Practice
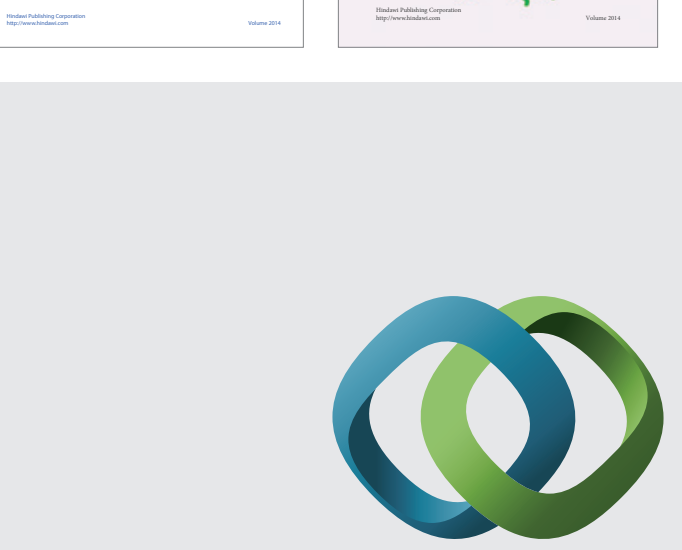

\section{Hindawi}

Submit your manuscripts at

http://www.hindawi.com
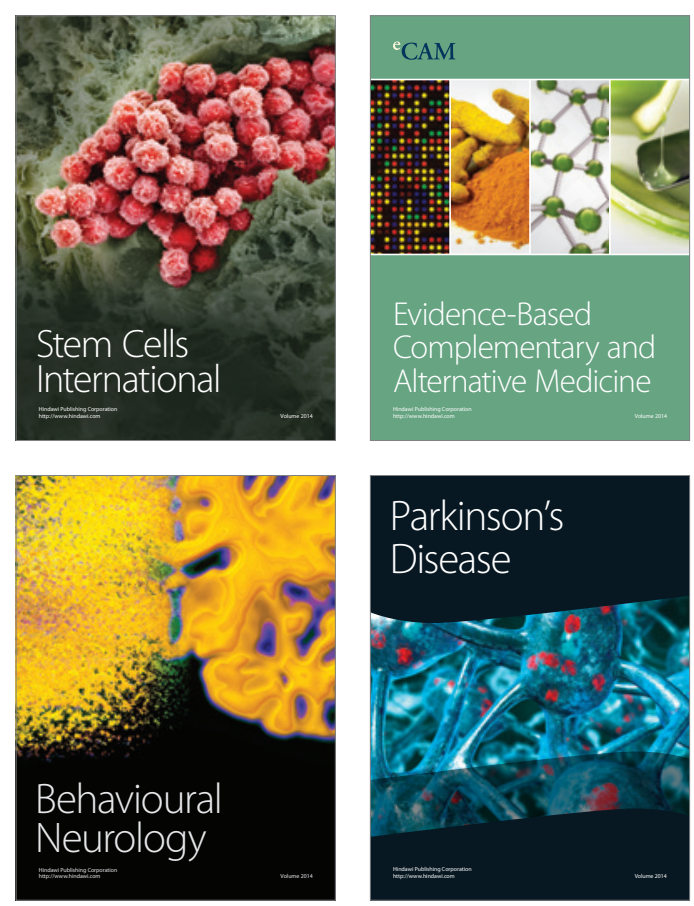

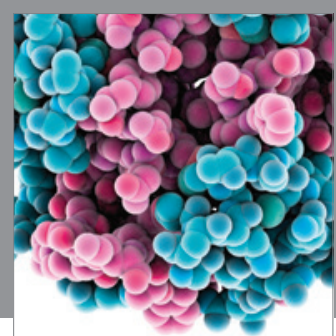

Journal of
Diabetes Research

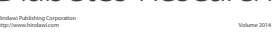

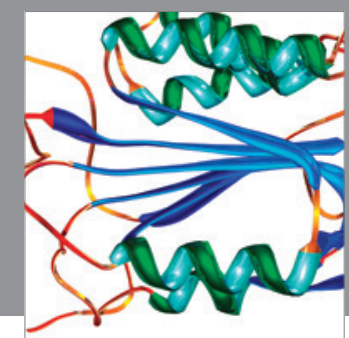

Disease Markers
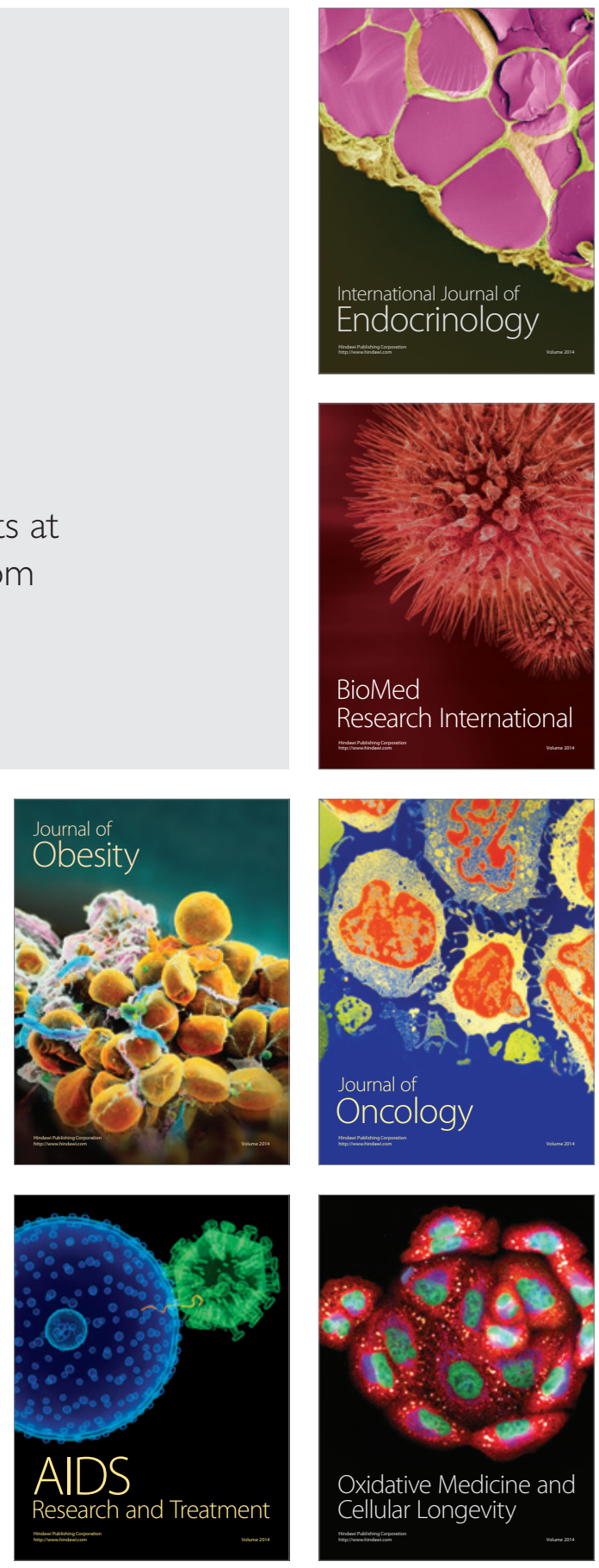